\title{
An Electron Microscope Study of Biomineralisation for Geotechnical Engineering Purposes
}

\author{
Stephen Wilkinson ${ }^{1}$ and Adharsh Rajasekar ${ }^{2}$ \\ ${ }^{1}$ Department of Civil Engineering, University of Wolverhampton, UK WV1 1LY \\ ${ }^{2}$ Nanjing University of Information science and technology-Reading Academy 219 Ningliu \\ road, Nanjing, Jiangsu, China 210044
}

\begin{abstract}
Directed biomineralisation, or using microorganisms to cause the formation of minerals, has been proposed as an effective method for permeability reduction and ground improvement. Where the precipitated mineral is a carbonate, heavy metal carbonates (e.g. otavite, malachite/azurite, cerussite, smithsonite, clearcreekite) can form, locking in heavy metal contamination. Where calcium carbonate forms there is an additional benefit of a high $\mathrm{pH}$ which, due to the buffering effect, can greatly reduce the mobility of heavy metal ions. Seven bacteria obtained from the soil \& landfill leachate environments in Suzhou China, were induced to precipitate calcium carbonate under laboratory conditions within a medium consisting of a calcium source, urea and nutrient broth in a conical flask. Trials within clean sand columns resulted in a permeability which was $1 / 5$ of that of a non-microbial column in addition to relative increases in strength of X3-5. On this basis, it is suggested that some geotechnical works using biomineralisation may be achieved without requiring external sources bacteria. This may be achieved either by isolating and growing the bacteria for application in the ground, or where growth can be achieved, by stimulating the bacteria in-situ. An electron microscope assessment of the mineral structures formed by the bacteria indicates that a variety of different crystal forms are generated by the biomineralisation process. Some crystal structures, especially the open crystal structures, are of less use for engineering purposes. This indicates that not all bacteria that can precipitate carbonates would be of use for achieving geotechnical aims.
\end{abstract}

Keywords: Biomineralisation, Ground Improvement, Environmental Protection, Crystal Structures, SEM analysis

\section{Introduction}

Microbial Geotechnology is a field of study that has been steadily expanding over the last 15 years. With a growing global focus on sustainability in engineering, assessments have been made of the potential for utilising natural processes to achieve engineering goals. Microbial processes have received particular attention and success especially for structural applications (Qian et al., 2015). 
One of the more popular microbial interventions in geotechnical engineering is microbially induced carbonate precipitation (MICP), and this process has been put forward for a wide range of geotechnical applications (Ivanov and Chu, 2008). These include stabilising soil against liquefaction (retaining walls, embankments, dams, slopes), strengthening the ground (tunnelling, bearing capacity), preventing slope erosion, constructing permeability barriers for containment of contamination, controlling river erosion, to name a few possibilities.

The MICP process involves injecting the carbonate precipitating bacteria into a sand system, alongside a calcium source, urea and a nutrient broth (Fig. 1 i). Variations in the concentration of components can produce differing results. Early experiments conducted by the authors, with low concentrations indicated the formation of carbonate bridging structures between particles (Fig. 1 ii). The process ultimately results in a solidified sand structure (Fig. 1 iii). The ultimate goals in using biomineralisation can be summarised as permeability reduction and/or ground improvement (Rajasekar et al., 2017a). MICP has been studied by a very wide range of authors (e.g. Harkes et al., 2010; Martinez et al., 2013; Neupane et al., 2013; DeJong et al., 2013; $\mathrm{Chu}$, 2014). Given that MICP is a biologically driven process whose main input materials are waste products, it has the potential to be a highly sustainable approach (Rajasekar et al., 2017b).
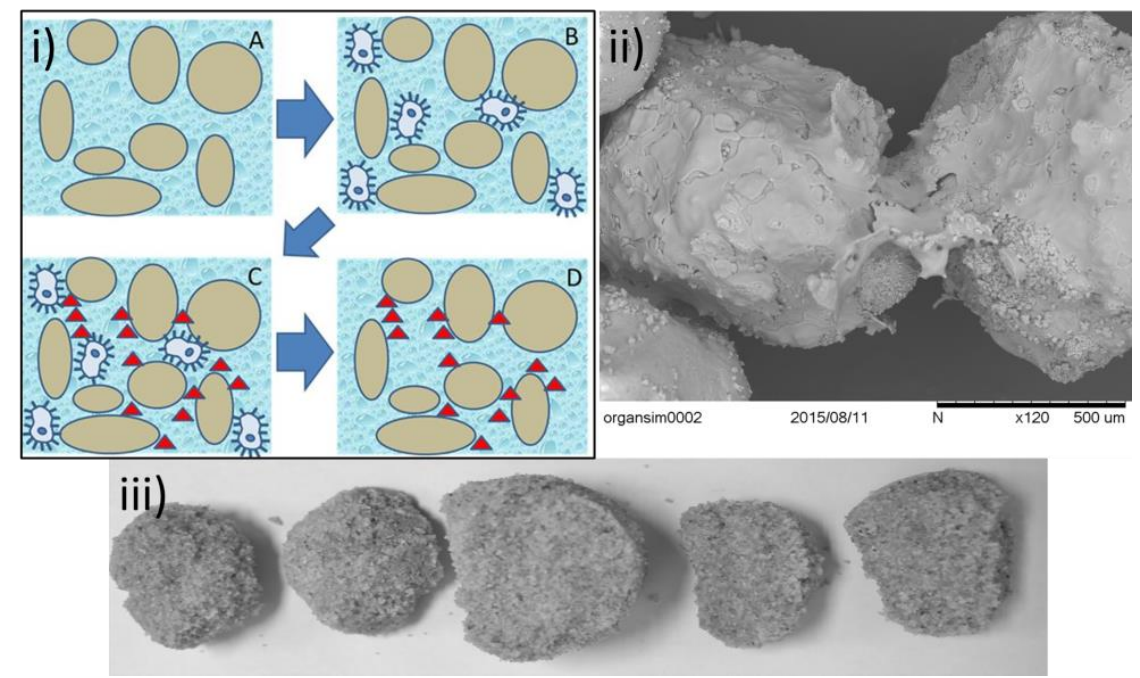

Fig. 1. The process for the biomineralisation of a soil specimen undertaken is summarised as: i) The original soil is injected with a biomineralisation medium that contains bacteria, a calcium source, urea and nutrients. The bacterial generate the environmental conditions in which $\mathrm{CaCO}_{3}$ can be deposited on the particle surfaces. The bacteria either die, are transported out of the system or are encased inside the minerals that they form. ii) Early experiments with low concentrations of biomineralising fluids, showing the produced connections between particles. iii) Broken sections from a biomineralised sand column sample, produced during this research project. 


\section{Experimental Methods}

Biomineralising organisms were isolated (using the spread plate method, purified with repeated streaking) from samples of landfill leachate and groundwater obtained from a landfill in Suzhou, China (Fig. 2). The bacteria were grown in a biomineralising medium in order to preferentially select for organisms with a higher propensity towards biomineralisation. The isolated organisms were identified, and those that were hazardous (1 of 8), were destroyed. The following 7 organisms were retained for testing: Bacillus licheniformis SZH2015_A, Bacillus pumilus szhxjlu2015, Bacillus sp. xjlu_herc15, Bacillus licheniformis adseedstjo15, Bacillus aerius rawirorabr15, Pseudomonas nitroreducens szh_asesj15 and Sphingopyxis sp. szh_adharsh. Initially, experiments were carried out by placing the $25 \mathrm{mM}$ Calcium chloride, $333 \mathrm{mM}$ Urea, nutrient broth and bacteria into a conical flask which was then placed in a rotary shaker inside an incubator. Samples of this liquid were studied under the optical microscope in order to assess the crystals formed.

As outlined below, the results of the flask experiments implied that the identified micro-organisms were able to enhance the production of calcium carbonate. With some of the more successful bacteria, further experiments aimed at the cementation of sand columns were carried out. Sand was placed, without compaction, into a column made from a section of drain pipe, the base of which is an end cap with a tap installed at the base. The system was made watertight using mastic (based on the design of Harkes et al., 2010). The biomineralizing media was added into the column and replaced every 24 hours during the experiment. The experiment continued for approximately 9 days. Following this, the permeability of the soil columns were calculated (in relation to a non-microbial blank column) based on the rate of downward flow of liquid placed in the top of each the column. Relative differences in strength were also measured using a pocket penetrometer (as an approximation). Finally, samples of the cemented material were transported to the, electron microscope imaging lab at Xi'an Jiaotong-Liverpool University, where microstructural images were taken, in order to assess the distribution of cementation between the sand grains. 


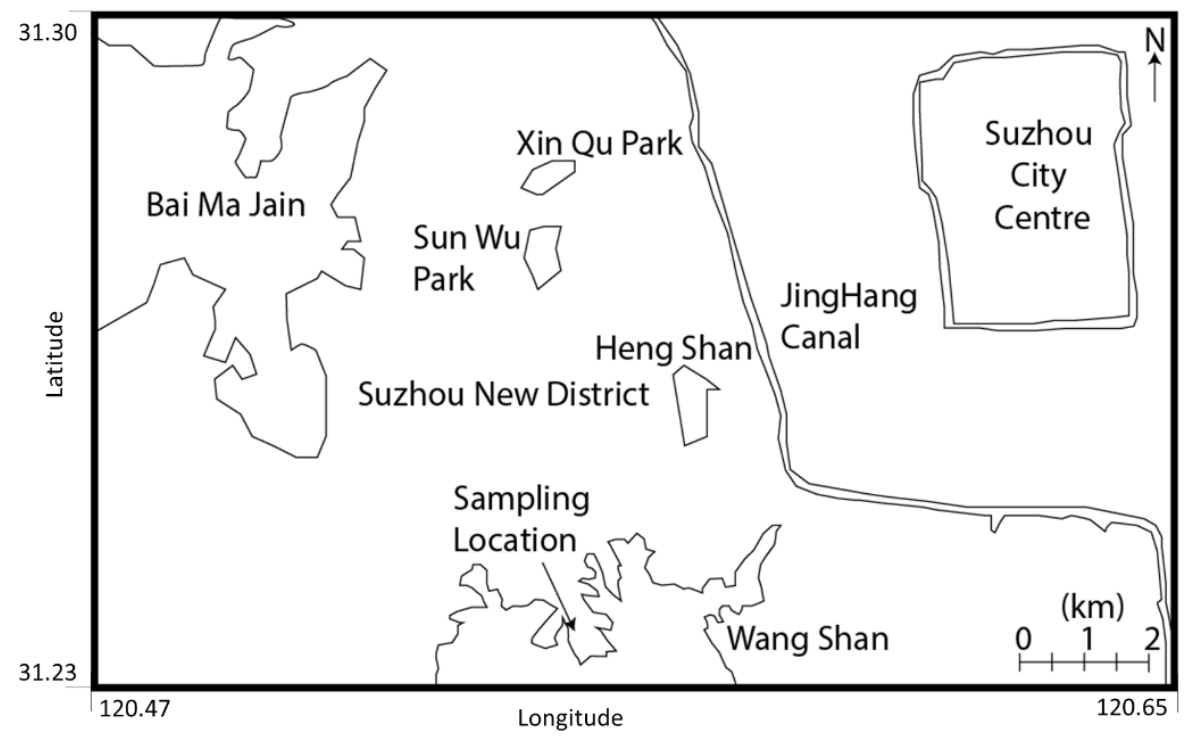

Fig. 2. Approximate map showing the sampling location in relation to major local geographical features.

\section{$3 \quad$ Results and Discussion}

Due to drying, which causes supersaturation, calcium carbonate crystals could form in layers aligned to the glass slide (Fig. 3 A). As a result, imaging of slides must occur rapidly. Typically, crystals formed due to biomineralisation take a more blocky form, often growing outwards from a central nucleation site (Fig. 3 B). Note that the bright points in the image (Fig. 3 B) were examined at a higher magnification and appeared to be the bacteria. Crystals were also observed being produced by Bacillus licheniformis adseedstjo15 (Fig. $3 \mathrm{C}$ ). Due to their birefringence colour, they are thought to be calcite, which implies they have formed during the MICP process. They were however not observed in all samples and so are likely to be related to the particular organism. Other combinations of crystals were also observed (Fig. 3 D).

The measured permeability was $\sim 5 \times 10^{-5} \mathrm{~m} / \mathrm{s}$ for all of the microbial samples, the non-microbial sample being 5 times higher at $2.5 \times 10^{-4} \mathrm{~m} / \mathrm{s}$. The strength of the samples varied from approximately $150-250 \mathrm{kPa}$ (UCS) in comparison to $\sim 50 \mathrm{kPa}$ for the non-microbial sample. Thus the UCS was improved by a factor of 3-5X.

Early experiments were carried out to assess the effects of drying of the biomineralising fluid on the sand grains. In the same way as in the optical microscope (Fig. 3A) the drying process within the electron microscope resulted in a supersaturation of the fluid causing the formation of skeletal calcium carbonate crystals (Fig. 4 A). Experiments with different organisms generated variations in the size and distribution of calcium carbonate crystals (Fig. 4). The size of the holes between particles is important for determining the resulting reduction in permeability that is achieved by the 
biomineralisation process. Generating an even groundmass between particles (Fig. 4 B) is useful as this will generate an even reduction in permeability across the soil. Increases in strength are generated through the formation of bridging crystals between particles (Fig. 4 C) which allow the transfer of stress through the soil. For some of the microbial samples, nucleation of crystals appears to be concentrated around grain contacts, which allows cementing boings to form, but may allow the more open spaces between particles to remain open, reducing the impact on permeability. In cases where the crystals formed by the organisms are large (Fig. 4 D), the gaps between the crystals may also be large, enhancing this potential effect.

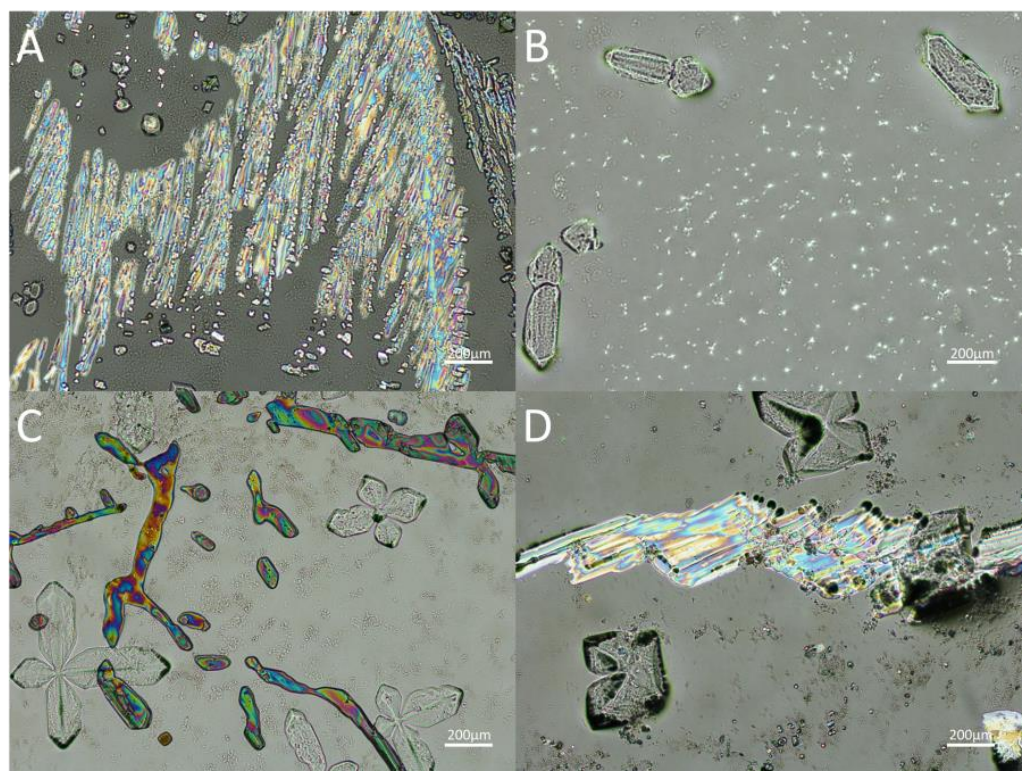

Fig. 3. Optical microscopic analysis of the final biomineralisation media, images are at X100 magnification, imaged in cross polarised light. A) Sample of calcite crystalisation caused by evaporation; B) crystals generated due to biomineralisation; C \& D) combinations of different types of crystals, coloured crystals in $\mathrm{C}$ are thought to be related to the micro-organisms, but are of unknown origin.

\section{Conclusions}

Experimentation with biomineralisation has resulted in the identifications of several potential applications within geotechnical engineering. The utilisation of locally sourced bacteria presents a potentially beneficial approach, as such bacteria are naturally present in the environment. Production of carbonate crystals within the abiotic media was found to be possible due to drying or through the natural hydrolysis of urea (which occurs much more slowly than in the presence of the bacterial enzyme urease). Note that calcium carbonate crystals can also form in a fluid rich in calcium due to the presence of atmospheric $\mathrm{CO}_{2}$. The extent of biomineralisation and the distribution of 
the products of biomineralisation varied with each organism. However, all produced a good enhancement in the cementing of the soil. The results indicate that within a soil bacteria with the potential to allow biomineralisation to some extent may be present. Coarse scale regional mapping of the presence or absence of geotechnically beneficial bacteria, would allow the use of in situ bacteria to be applied with excessive prior investigation, allowing this more sustainable technique to be appropriately and more readily applied.

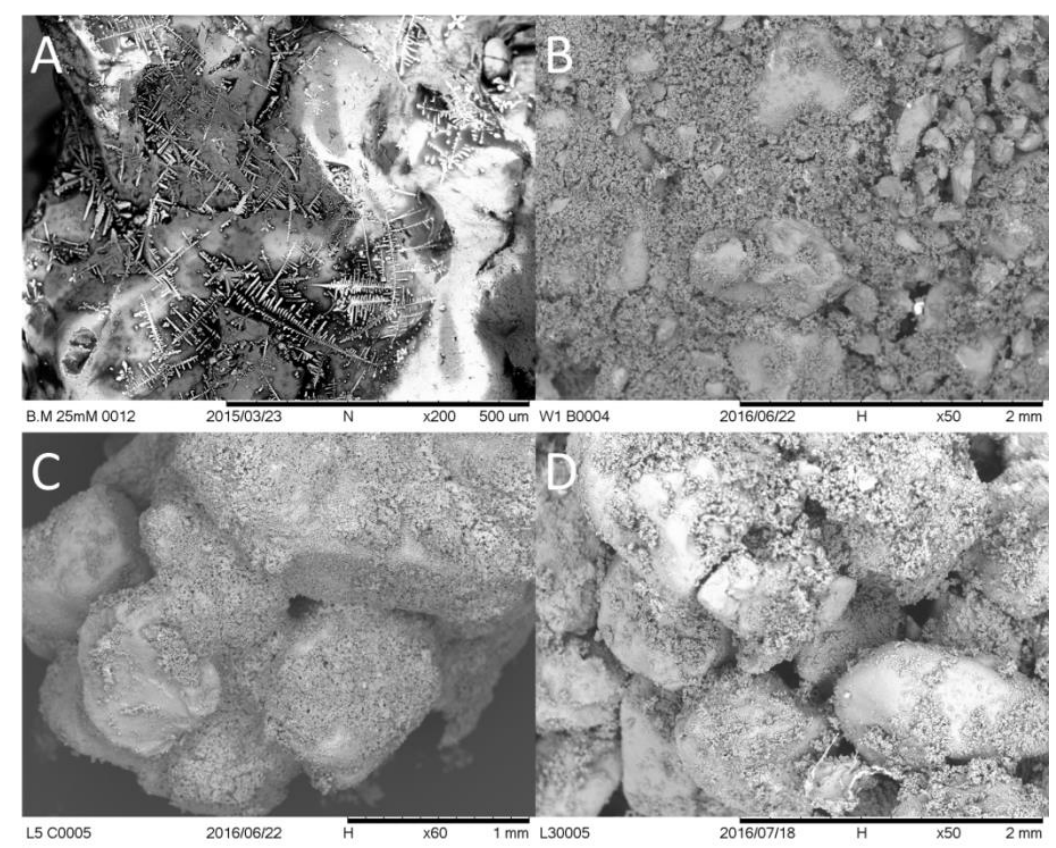

Fig. 4. Scanning Electron Microscope (SEM) images of sand samples A) supersaturation during drying causing the rapid formation of skeletal calcium carbonate crystals. B, C, \& D all show cemented particles generated by different organisms. B) groundmass of crystals formed between particles, a few larger quartz sand grains are visible. C) Cluster of grains held together by MICP generated calcium carbonate crystals, some large voids between particles are present. D) larger, but more well-spaced crystals are formed, the surface of some particles are visible and larger gaps can be seen between particles.

\section{References}

Chu, J., Ivanov, V., Naeimi, M., Stabnikov, V., Liu, H.-L.: Optimization of calcium-based bioclogging and biocementation of sand. Acta Geotechnica, 9, 277-285 (2014).

DeJong, J.T., Soga, K., Kavazanjian E., Burns, S., Van Paassen, L.A., Al Qabany, A., Aydilek, A., Bang, S.S., Burbank, M., Caslake, L. F., Chen, C.Y., Cheng, X., Chu, J., Ciurli, S., Esnault-filet, A., Fauriel, S., Hamdan, N., Hata, T., Inagaki, Y., Jefferis, S., Kuo, M., Laloui, L., Larrahondo, J., Manning, D.A.C., Martinez, B., Montoya, B.M., Nelson, D.C., Palomino, 
A., Renforth, P., Santamarina, J.C., Seagren, E.A., Tanyu, B., Tsesarsky, M., Weaver, T.: Biogeochemical processes and geotechnical applications: progress, opportunities and challenges. Géotechnique 63(4), 287-301 (2013).

Harkes, M.P., van Paassen, L.A., Booster, J.L., Whiffin, V.S., van Loosdrecht, M.C.M.: Fixation and distribution of bacterial activity in sand to induce carbonate precipitation for ground reinforcement. Ecological Engineering 36(2), 112-117 (2010).

Ivanov, V., Chu, J.: Applications of microorganisms to geotechnical engineering for bioclogging and biocementation of soil in situ. Reviews in Environmental Science and Bio/Technology 7(2), 139-153 (2008).

Martinez, B.C., DeJong, J.T., Ginn, T.R., Montoya, B.M., Barkouki, T.H., Hunt, C. Tanyu, B. Major, D.: Experimental optimization of microbial-induced carbonate precipitation for soil improvement. Journal of Geotechnical and Geoenvironmental Engineering 139(4), 587-598 (2013).

Neupane, D., Yasuhara, H., Kinoshita, N., and Unno, T.: Applicability of enzymatic calcium carbonate precipitation as a soil-strengthening technique. Journal of Geotechnical and Geoenvironmental Engineering 139(12), 2201-2211 (2013).

Qian, X-Y., Zhang, Q., Wilkinson, S., Achal, V.: Cleaning of historic monuments: Looking beyond the conventional approach?. Journal of Cleaner Production. 101, 180-181 (2015).

Rajasekar, A., Moy, C.K.S., Wilkinson, S.: Stimulation of indigenous carbonate precipitating bacteria for ground improvement. IOP Conference Series Earth and Environmental Science 68(1), 012010 (2017a).

Rajasekar, A., Moy, C.K.S., Wilkinson, S.: MICP and Advances towards eco-friendly and economical applications. IOP Conference Series Earth and Environmental Science 78(1), 012016 (2017b). 